\title{
Predictors of Course and Outcome in Hypochondriasis after Cognitive-Behavioral Treatment
}

\author{
Wolfgang Hiller ${ }^{a}$ b Rolf Leibbrand ${ }^{b}$ Winfried Riefc Manfred M. Fichtera,d \\ aRoseneck Center of Behavioral Medicine, Prien, bPsychological Institute, University of Mainz, \\ 'Psychological Institute, University of Marburg, dDepartment of Psychiatry, University of Munich, Germany
}

\section{Key Words}

Hypochondriasis · Predictors · Prognosis .

Cognitive-behavioral treatment · Somatoform disorders

\begin{abstract}
Background: Predictors of treatment outcome were evaluated in a clinical sample suffering from hypochondriasis. Methods: The sample consisted of 96 patients with hypochondriacal disorder according to DSM-IV or high syndrome scores on the Illness Attitude Scales (IAS) or Whiteley Index (WI). After intense inpatient cognitivebehavioral treatment (CBT), $60 \%$ of the patients were classified as responders because of substantial improvements or recovery from hypochondriacal symptomatology. Results: Non-responders were characterized by a higher degree of pre-treatment hypochondriasis, more somatization symptoms and general psychopathology (SCL-90R), more dysfunctional cognitions related to bodily functioning, higher levels of psychosocial impairments, and more utilization of the health care system as indicated by the number of hospital days and costs for inpatient treatments and medication. No predictive value was found for sociodemographic variables, comorbidity with other mental disorders and chronicity. Multiple
\end{abstract}

linear regression showed that pre-treatment variables significantly predicted IAS scores at post-treatment $\left(\mathrm{R}^{2}=\right.$ $0.59)$, changes during treatment $(0.10)$, IAS scores at follow-up two years later (0.41) and changes between baseline and follow-up (0.25). Conclusions: The results demonstrate the relevance of various psychopathological variables and health care utilization as important indicators for outcome and further course of clinical hypochondriasis.

Copyright @2002S. Karger AG, Basel

Hypochondriasis is a traditional diagnosis related to health anxieties and perceived disturbances of bodily functioning. According to modern nosology, hypochondriacal patients are considered as somatoform because most of them suffer from somatic complaints for which no organic reasons can be found [1]. The health anxieties may dominate the clinical picture either alone or secondary to other symptomatology such as depressive or anxiety disorders [2, 3]. The exact etiology of hypochondriasis is not known. Some findings suggest that misinterpretations of benign bodily symptoms as signs of a serious disease play an important role [4, 5]. Hypochondriacal patients show selective attention towards even minor sen-

\begin{tabular}{ll}
\hline KARGER & ( ) 2002 S. Karger AG, Basel \\
Fax +4161306 1234-3190/02/0716-0318\$18.50/0 \\
$\begin{array}{l}\text { E-Mail karger@karger.ch } \\
\text { www.karger.com }\end{array}$ & $\begin{array}{l}\text { Accessible online at: } \\
\text { www.karger.com/journals/pps }\end{array}$
\end{tabular}

Prof. Dr. Wolfgang Hiller

Psychological Institute, University of Mainz

Staudingerweg 9

D-55099 Mainz (Germany)

Tel. +49 6131 3922344, Fax +496131 3924623, E-Mail hiller@mail.uni-mainz.de 
sations in their body, are over-concerned with their physical functioning, and habituate less to somatosensory input [6]. Illness behaviors such as doctor shopping and excess utilization of health care are considered as maintenance factors [7], frequently associated with widespread impairments in psychosocial functioning [8]. Many of these factors seem to interact in complex ways, as recently outlined by Fava and Sonino [9] for clinical conditions in the field of psychosomatic medicine.

Little is known about the natural course of hypochondriacal disorder. Episodes of transient hypochondriasis seem to be a common phenomenon of everyday life [10] and are frequently observed in general medical patients [11]. However, severe health anxieties may also persist over long periods of time. The DSM-IV diagnosis of hypochondriasis requires a minimum duration of six months. Robbins and Kirmayer [12] differentiated between transient, emerging and persistent hypochondriasis in a oneyear follow-up study of hypochondriacal patients. They found that the strongest predictors for persistent hypochondriasis were comorbid depressive or anxiety disorders, fears of emotional instability, pathological symptom attributions and interpersonal vulnerability.

Facing the severe distress and disabilities of hypochondriacal patients, treatment strategies were developed for this clinical group based on cognitive-behavioral theory. Body-related cognitive dysfunctions and associated illness behaviors are taken into account by interventions such as those described by Bouman and Visser [13] or Warwick and Salkovskis [14]. They aim at interrupting the vicious circle of selective attention and misinterpretation, health anxieties, maladaptive behaviors in the medical system, psychopathology and psychosocial impairments. The effectiveness of cognitive-behavioral therapy (CBT) for hypochondriacal patients has been demonstrated in different clinical and controlled studies [1518].

Data about more long-standing effects of CBT are available only for the heterogeneous group of somatoform disorders and not specifically for hypochondriasis. Rief et al. [19] reported that $27 \%$ of patients were in remission two years after inpatient CBT. Prognosis was better when the somatoform disorder had not been complicated by comorbid depressive or anxiety disorders. Speckens et al. [20] found higher remission rates, lower symptom intensity and less functional impairment in terms of social interactions and illness behavior in general medical outpatients one year after outpatient CBT, as compared to patients who had received optimized medical care.
Despite these encouraging results, almost nothing is known about factors predicting response and long-term outcome of CBT. It has not yet been evaluated which patients are responders and which fail to have treatment success. The only predictor study known to us is the one by Speckens et al. [21] who found that dimensional scores of hypochondriasis were negatively related with recovery one year later, illness behavior scores were predictive of the number of visits to the general practitioner, and hypochondriacal patients had less remission than somatizing patients without hypochondriasis. However, the sample described by these authors had only received clinical care and not CBT, and the strength of prediction was not directly analyzed because outcome was categorized and only $\beta$-weights of linear regression were reported.

We conducted a prospective study to evaluate which factors influence treatment effects and predict the clinical status immediately after treatment and two years later. The methodological aims of the study were (1) to differentiate between responders and non-responders of inpatient CBT for hypochondriasis, and (2) to examine whether single or combined pre-treatment variables were of prognostic value and how strongly.

\section{Methods}

\section{General Procedure and Setting}

An inpatient treatment program for patients suffering from somatoform disorders and health anxieties was implemented and evaluated at the Roseneck Center for Behavioral Medicine, a researchoriented hospital affiliated with the Medical Faculty of the University of Munich. Our approach was developed according to current principles and techniques of CBT. In the present paper, we will focus on patients diagnosed as hypochondriacal disorder or presenting with a syndrome of health anxieties as measured by clinical rating scales. A large number of sociodemographic and other pre-treatment variables were assessed to serve as potential predictors. Patients completed a battery of self-rating scales focusing on psychopathology and psychosocial impairments at baseline (pre-treatment), discharge (post-treatment) and again at the two-year follow-up.

As a regular tertiary care hospital, the Roseneck Center is representative for inpatient mental health treatment in Germany. It is accessible to the general population, irrespective of social and vocational status. Treatment indications cover all mental and psychophysiological disorders except schizophrenia and related psychotic disorders, acute manic episodes, and severe disorders due to psychoactive substances. As described in earlier studies [e.g., 8, 19], patients referred to the Roseneck Center represent a high-risk group for somatoform disorders.

\section{Sample Selection and Diagnostic Methods}

Patients were consecutively selected if there was evidence of unclear physical symptoms or health anxieties from the letters of the referring clinicians, available medical records or the personal reports 
of the patients themselves. We excluded cases of primary eating disorders or chronic tinnitus because these groups are treated in other specialized departments. Based on these criteria, 324 patients were selected for further diagnostic examination. They received a thorough medical examination to rule out that the symptoms were due to organic disease. In addition, other DSM-IV mental disorders were systematically screened for to obtain a profile of comorbidity. We performed detailed face-to-face interviews using the Structured Clinical Interview (SCID) [22] and the International Diagnostic Checklists (IDCL) [23, 24]. Patients were included only after giving written informed consent to participate in the study.

\section{Defining Patients with Clinical Hypochondriasis}

Of the 324 patients originally selected, 59 were found to meet the DSM-IV criteria of current hypochondriacal disorder. Another 44 patients had high pre-treatment scores on two hypochondriasis scales, the Illness Attitude Scales (IAS) and the Whiteley Index (WI). The IAS was originally developed by Kellner [25, 26; see also 27] and consists of 29 items which are to be rated on five-point Likert scales. Although Kellner had originally defined nine a-priori scales with three items per scale, a re-analysis reported by Speckens et al. [21] and confirmed by us [28] suggests that two main dimensions labeled 'health anxieties' and 'illness behavior' can be differentiated. The WI is an internationally established short hypochondriasis scale developed by Pilowsky [29]. We used a 10-item version for which we demonstrated that maximum specificity and sensitivity against the clinical DSM-IV diagnosis of hypochondriasis is reached. All items of the WI were coded dichotomously (true-false). Based on these questionnaires, we defined a clinically relevant syndrome of hypochondriasis as a score of $\geq 43$ on the IAS or $\geq 6$ on the WI. These cut-off values were derived from previous analyses as discriminating best between hypochondriacal and non-hypochondriacal subjects [28].

Our hypochondriacal sample thus consisted of patients with DSM-IV hypochondriacal disorder or high IAS/WI scores. The latter patients missed the DSM-IV criteria mainly because they could not name a specific feared disease (but were afraid that something undefined was wrong with their body) or reported that their health anxieties had not continuously persisted over at least 6 months. Their DSM-IV comorbidity profile mainly included diagnoses of major depression $(84.1 \%)$, social phobia (38.6\%), panic disorder $(27.3 \%)$, agoraphobia (22.7\%) and substance use disorders (22.7\%).

\section{The Treatment Program}

Treatment was interdisciplinary and followed the principles of CBT and behavioral medicine. Patients received individual and group psychotherapy at least once every day. As described by Bouman and Visser [13] or Warwick and Salkovskis [14], special attention was given to emotions, cognitions and behaviors related to bodily complaints and health anxieties. The main therapeutic techniques included identification and modification of dysfunctional perceptions and thoughts. Longer-range goals were to increase self-care, encourage physical activity, improve interpersonal and occupational functioning, and lessen dependency on the medical care system. The patients were also educated about the nature of their symptoms and possible psychophysiological mechanisms relevant for the development and maintenance of their complaints. Such techniques are part of explanatory therapy, as developed by Kellner [30] and recently evaluated by Fava et al. [31]. Pure medical consultations and medications were kept to a minimum to enhance the use of psychological coping skills. When appropriate, we performed systematic physical exercises with the patients in order to improve their bodily functioning and change their negative self-concept of being weak and disabled. Other treatment components were assertiveness training, progressive relaxation and biofeedback sessions in which interactions between physical and mental processes were demonstrated. All clinicians received concise treatment guidelines and a series of training sessions. The complete program was summarized by us in a German treatment manual [32].

\section{Definition of Responders and Non-Responders}

IAS and WI were used not only to assess the degree of hypochondriasis but also to define whether or not individual patients improved during treatment. Patients were considered responders according to two criteria: (1) improvement of at least $20 \%$ between baseline and discharge on the total scores of the IAS or WI, or (2) post-treatment IAS score $\leq 20$ or WI score $\leq 3$ (these scores indicate the absence of clinically relevant hypochondriacal symptomatology).

Based on these criteria, 58 patients $(60.4 \%)$ were classified as responders and $38(39.6 \%)$ as non-responders. Seven patients from the previously described hypochondriacal group could not be included because of incomplete questionnaires at discharge. Our total sample thus consisted of 96 patients. Their female proportion was $58.3 \%$ and their mean age 47.0 years $(\mathrm{SD}=10.3)$ with a range between 26 and 72 years. Further details about sociodemographic and clinical characteristics will be given below. The mean treatment length for the complete sample was 57.5 days $(\mathrm{SD}=18.5)$ with no significant difference between the responder and non-responder subgroups $(\mathrm{t}=0.12, \mathrm{df}=94, \mathrm{p}>0.05)$.

\section{Predictor Variables}

A broad list of personal, demographic, psychopathological and psychosocial variables were assessed at pre-treatment.

Sociodemographic Characteristics. Age, sex, years of school or academic education, and familial status were recorded for each patient.

Pre-Treatment Measures of Psychopathology. We assessed the degree of somatization, depression and general psychopathology by means of self-rating scales: (1) the Screening for Somatoform Symptoms (SOMS), a validated index of medically unexplained physical symptoms referring to the symptom lists of DSM-IV and ICD-10 (the SOMS trait version gives the number of symptoms during the past two years, the state version the number and degree of physical complaints during the past seven days) [33]; (2) the Beck Depression Inventory (BDI), a dimensional scale of depressive symptomatology [34]; (3) the revised Symptom Checklist (SCL-90R), a widely used instrument to assess general psychopathology with 90 items on nine dimensions [35].

Pre-Treatment Cognitive Distortions. Based on a cognitive-behavioral perspective, the Cognitions About Body and Health Questionnaire (CABAH) had been developed by Rief et al. [5] to assess problematic cognitions and attitudes associated with bodily complaints, extending and elaborating the 10-item Somatosensory Amplification Scale proposed by Barsky et al. [36]. The CABAH used in our study consists of 31 statements which define the following five subscales: catastrophizing interpretation of bodily complaints, autonomic sensations, bodily weakness, intolerance of bodily complaints, and health habits. 
Comorbidity. Information about the presence or absence of any additional DSM-IV axis I disorders was available from the detailed standardized diagnostic interviews (see above).

Pre-Treatment Psychosocial Impairment. Our primary measure to assess psychosocial functioning was the Dysfunctional Analysis Questionnaire (DAQ) which had been employed in previous studies with somatoform patients [8, 37]. The 45 items of the instrument can be divided into five scales describing impairments in the following areas: social, vocational, personal, familial, and cognitive. Each item is rated on a five-point scale, comparing the present level of functioning with that before the onset of the disorder. We also interviewed each patient on how many weeks she or he had been unable to work during the past twelve months.

Chronicity. The number of years since onset of the disorder was registered as based on the patients' reports.

Pre-Treatment Use of Health Services. We assessed several measures related to health care utilization. Based on medical and billing records of the patients' health insurance companies, we re-calculated expenditures made for outpatient and inpatient treatments as well as costs for prescribed medications. These data refer to the two-year period before treatment. In addition, the number of days spent in a hospital during the past year was registered.

\section{Statistics}

Simple and multiple regression analysis were used to evaluate the contribution of single variables and variable sets to predicting treatment outcome. The strength of prediction is expressed by the amount of variance of the criteria variable accounted for by the predictor variables. The amount of explained (common) variance is equivalent to squared correlation coefficients in simple regression $\left(\mathrm{r}^{2}\right)$ and squared multiple correlations in multiple regression $\left(\mathrm{R}^{2}\right)$. Since we also divided our sample into responders and non-responders, group means were compared by Student's $t$ tests and proportions by $\chi^{2}$ analyses. Since not all data distributions were normal, we additionally performed Mann-Whitney U tests. Because these yielded results similar to those of the $t$ tests, only the $t$ values are reported here. The $\alpha$ significance level was conventionally set to 0.05 .

\section{Results}

\section{Comparison of Responders and Non-Responders}

Table 1 shows that the degree of pre-treatment hypochondriasis was significantly higher in non-responders in the IAS (total score) but not in the WI. While no sociodemographic variables predicted group membership, nonresponders had significantly higher scores in the SOMS (state version), SCL-90R, CABAH and DAQ. They also reported a greater number of days not able to work in the twelve-month period prior to treatment, had more expenses for inpatient care and prescribed medication, and spent more days in hospitals. Although substantial rates of comorbid affective and anxiety disorder were found, neither the additional diagnoses of major depression nor panic disorder were significant predictors (all other DSMIV mental disorders were also not predictive for treatment response). Chronicity of the symptomatology was also not different between both groups.

\section{Relevance of Single Predictors}

To estimate the strength of prediction, we calculated how much variance of the dependent variables was accounted for by the individual predicting variables (table 2). Four criteria to be predicted were defined: (1) posttreatment IAS scores, (2) short-term treatment effects on the IAS as indicated by the difference between pre- and post-treatment scores, (3) IAS scores at the two-year follow-up examination, and (4) long-term treatment effects on the IAS as indicated by the difference between pretreatment and two-year follow-up scores. Table 2 considers only variables which had differentiated in table 1 between the responder and non-responder groups. IAS scores at post-treatment and follow-up were best predicted by pre-treatment IAS, SOMS-state, SCL-90R, $\mathrm{CABAH}, \mathrm{DAQ}$ and medication expenses. Inpatient treatment costs and the number of days spent in hospitals predicted the patients' condition at follow-up but not immediately after treatment. Change during treatment was predicted only by CABAH and the disability to work, while long-term changes were linked to pre-treatment IAS, SCL90R, inpatient treatment expenses and number of days spent in hospitals. Interestingly, almost all correlations with difference scores were negative, which means that higher scores in the pre-treatment variable were associated with less improvement. The only exception are the IAS scores which were positively related to outcome. It becomes evident from table 2 that the clinical status of the patients at post-treatment and follow-up is generally better predictable than improvements between two points of measurement.

When predictors were analyzed on the level of subscales, we found that patients with less catastrophizing thinking (CABAH-I, $4.7 \%$ of variance explained, $\mathrm{p}<$ $0.05)$ and less health habits (CABAH-V, 7.0\%, p < 0.05) improved stronger during treatment. The degree of occupational impairments (DAQ-II, $4.9 \%, \mathrm{p}<0.05$ ) was also negatively associated with treatment outcome (difference scores). High scores on the SCL-90R subscale paranoid ideation predicted less improvement between pre-treatment and follow-up $(6.9 \%, \mathrm{p}<0.05)$. The original IAS scales proposed by Kellner [25, 26] produced generally weaker predictions than the factor analytically derived IAS score used by us. 
Table 1. Comparison of responders and non-responders

\begin{tabular}{|c|c|c|c|c|}
\hline & $\begin{array}{l}\text { Responders } \\
(\mathrm{n}=58)\end{array}$ & $\begin{array}{l}\text { Non-responders } \\
(\mathrm{n}=38)\end{array}$ & Significance & \\
\hline \multicolumn{5}{|l|}{ Pre-treatment severity of hypochondriasis } \\
\hline IAS & $51.4(11.0)$ & $57.4(11.9)$ & $\mathrm{t}=2.52(\mathrm{df}=94)$ & $\mathrm{p}<0.01$ \\
\hline WI & $7.46(1.80)$ & $7.58(1.75)$ & $\mathrm{t}=0.34(\mathrm{df}=94)$ & n.s. \\
\hline \multicolumn{5}{|l|}{ Sociodemographic } \\
\hline Age & $45.6(9.3)$ & $49.2(11.5)$ & $\mathrm{t}=1.73(\mathrm{df}=94)$ & n.s. \\
\hline Female & $63.8 \%$ & $50.0 \%$ & $\chi^{2}=1.27(\mathrm{df}=1)$ & n.s. \\
\hline Education $\leq 9$ years & $55.2 \%$ & $52.6 \%$ & $\chi^{2}=0.01(\mathrm{df}=1)$ & n.s. \\
\hline Married & $60.3 \%$ & $73.7 \%$ & $\chi^{2}=1.27(\mathrm{df}=1)$ & n.s. \\
\hline Divorced & $6.9 \%$ & $5.3 \%$ & $\chi^{2}=0.00(\mathrm{df}=1)$ & n.s. \\
\hline \multicolumn{5}{|c|}{ Pre-treatment measures of psychopathology } \\
\hline SOMS-trait & $17.5(7.2)$ & $18.7(8.9)$ & $\mathrm{t}=0.72(\mathrm{df}=93)$ & n.s. \\
\hline SOMS-state & $39.1(25.4)$ & $50.6(27.6)$ & $\mathrm{t}=2.08(\mathrm{df}=94)$ & $\mathrm{p}<0.05$ \\
\hline BDI & $24.0(10.2)$ & $27.4(9.2)$ & $t=1.64(d f=92)$ & n.s. \\
\hline SCL-90R (positive symptom total) & $59.4(18.1)$ & $68.2(13.8)$ & $\mathrm{t}=2.51(\mathrm{df}=89)$ & $\mathrm{p}<0.01$ \\
\hline \multicolumn{5}{|l|}{ Pre-treatment cognitive distortions } \\
\hline CABAH & $45.4(13.3)$ & $53.0(11.8)$ & $\mathrm{t}=2.83(\mathrm{df}=91)$ & $\mathrm{p}<0.01$ \\
\hline \multicolumn{5}{|l|}{ Comorbidity } \\
\hline Major depression & $70.7 \%$ & $84.2 \%$ & $\chi^{2}=1.62(\mathrm{df}=1)$ & n.s. \\
\hline Panic disorder & $32.8 \%$ & $23.7 \%$ & $\chi^{2}=0.53(\mathrm{df}=1)$ & n.s. \\
\hline \multicolumn{5}{|l|}{ Pre-treatment psychosocial impairment } \\
\hline DAQ & $66.6(14.7)$ & $72.3(13.6)$ & $t=1.91(\mathrm{df}=94)$ & $\mathrm{p}<0.05$ \\
\hline No. weeks not able to work ${ }^{\mathrm{a}}$ & $11.8(17.1)$ & $21.5(18.29)$ & $\mathrm{t}=2.32(\mathrm{df}=72)$ & $\mathrm{p}<0.05$ \\
\hline \multicolumn{5}{|l|}{ Chronicity } \\
\hline No. years since onset & $9.4(9.2)$ & $10.6(9.8)$ & $\mathrm{t}=0.56(\mathrm{df}=92)$ & n.s. \\
\hline \multicolumn{5}{|l|}{ Pre-treatment use of health services } \\
\hline Outpatient treatment expenses ${ }^{b}$ & $908(920)$ & $760(503)$ & $\mathrm{t}=0.61(\mathrm{df}=45)$ & n.s. \\
\hline Inpatient treatment expenses ${ }^{b}$ & $1,020(1,887)$ & $2,037(3,229)$ & $\mathrm{t}=1.68(\mathrm{df}=69)$ & $\mathrm{p}<0.05$ \\
\hline Medication expenses ${ }^{\mathrm{b}}$ & $205(246)$ & $437(460)$ & $\mathrm{t}=1.71(\mathrm{df}=25)$ & $\mathrm{p}<0.05$ \\
\hline No. days in hospital b & $12.0(23.1)$ & $26.9(38.3)$ & $\mathrm{t}=2.05(\mathrm{df}=69)$ & $\mathrm{p}<0.05$ \\
\hline
\end{tabular}

For continuous variables, means and standard deviations (in brackets) are displayed; for categorical variables, percentage proportions are displayed. n.s. = Not significant in one-tailed tests.

a Refers to the twelve-month period before admission.

b Refers to the two-year period before admission, values are given in EUR.

\section{Multiple Regression Analysis}

To elucidate the combined predictive power of several measures, multiple regression analysis with simultaneous entry of variables was computed. We included only those predictors that had been reported in table 2 as significantly related to the individual criteria (only medication costs were excluded because of the relatively small number of cases for which these data were available). As can be seen from table 3 , the best overall predictions were obtained for the IAS scores. $58.9 \%$ of the post-treatment and $41.4 \%$ of the follow-up IAS variance were accounted for by the entered variables. Improvements between pre- and posttreatment $(9.9 \%)$ and between pre-treatment and follow- up (24.9\%) were also predicted beyond statistical significance, although these associations were clearly weaker.

Since pre-treatment severity of hypochondriasis predicted treatment response, it seemed necessary to repeat the multiple regression analyses by controlling for pretreatment IAS scores. We therefore forced pre-treatment IAS into the regression model as the first independent variable and analyzed whether the remaining variables still predicted significantly. $52.5 \%$ variance of the posttreatment IAS scores were explained by pre-treatment IAS alone and an additional proportion of $6.4 \%$ by the other five predictors, which was only marginally significant $(\mathrm{F}=2.08, \mathrm{df}=5,67, \mathrm{p}=0.08)$. The relevance of pre- 
Table 2. Strength of prediction

\begin{tabular}{lccll}
\hline Pre-treatment variables & $\begin{array}{l}\text { IAS score } \\
\text { post-treatment }\end{array}$ & $\begin{array}{l}\text { IAS difference } \\
\text { pre- vs. post- } \\
\text { treatment }\end{array}$ & $\begin{array}{l}\text { IAS score } \\
\text { 2-year } \\
\text { follow-up }\end{array}$ & $\begin{array}{l}\text { IAS difference } \\
\text { pre-treatment } \\
\text { vs. follow-up }\end{array}$ \\
\hline IAS & $52.5^{+, * *}$ & $<0.1$ & $24.9^{+, * *}$ & $6.1^{+, *}$ \\
SOMS-state & $9.8^{+, * *}$ & $<0.1$ & $10.9^{+, * *}$ & 0.1 \\
SCL-90R (positive symptom total) & $9.0^{+, * *}$ & 0.8 & $17.3^{+, * *}$ & $5.3^{-, *}$ \\
CABAH & $18.8^{+, * *}$ & $6.3^{-, *}$ & $11.4^{+, * *}$ & 1.0 \\
DAQ & $7.7^{+, * *}$ & 1.2 & $7.6^{+, *}$ & 0.6 \\
Weeks not able to work & $13.3^{+, * *}$ & $6.6^{-, *}$ & $3.8^{+, *}$ & 0.1 \\
Inpatient treatment expenses (EUR) & 1.0 & 0.1 & $10.1^{+, *}$ & $6.5^{-, *}$ \\
Medication expenses (EUR) & $18.0^{+, *}$ & 0.4 & $23.2^{+, *}$ & 0.8 \\
No. days in hospital & 0.9 & $<0.1$ & $12.9^{+, * *}$ & $7.8^{-, *}$ \\
\hline
\end{tabular}

Strength of prediction is expressed as variance proportions, i.e. the amount of variance of the criterion variable accounted for by the predicting variable. ${ }^{*} \mathrm{p}<0.05,{ }^{* *} \mathrm{p}<0.01$; it is additionally indicated for each significant prediction whether the correlation between pre-treatment variable and predicted variable is positive $(+)$ or negative (-).

Table 3. Results from multiple regression analysis

\begin{tabular}{lllll}
\hline & \multicolumn{2}{l}{ Predicted criteria } & \\
\cline { 2 - 5 } & $\begin{array}{l}\text { IAS score } \\
\text { post-treatment }\end{array}$ & $\begin{array}{l}\text { IAS difference } \\
\text { pre- vs. post- } \\
\text { treatment }\end{array}$ & $\begin{array}{l}\text { IAS score } \\
\text { 2-year } \\
\text { follow-up }\end{array}$ & $\begin{array}{l}\text { IAS difference } \\
\text { pre-treatment } \\
\text { vs. follow-up }\end{array}$ \\
\hline $\begin{array}{l}\text { Predictors } \\
\mathrm{R}^{2}\end{array}$ & 6 & 2 & 7 & 4 \\
Significance & 0.589 & 0.099 & 0.414 & 0.249 \\
& $\begin{array}{l}\mathrm{F}=16.0^{* *} \\
\mathrm{df}=6,67\end{array}$ & $\begin{array}{l}\mathrm{F}=3.88^{*} \\
\mathrm{df}=2,71\end{array}$ & $\begin{array}{l}\mathrm{F}=5.36^{* *} \\
\mathrm{df}=7,61\end{array}$ & $\begin{array}{l}\mathrm{F}=4.63^{* *} \\
\mathrm{df}=4,56\end{array}$ \\
\hline
\end{tabular}

$* \mathrm{p}<0.05 ; * * \mathrm{p}<0.01$ treatment hypochondriasis was clearly smaller for the follow-up period. $16.5 \%$ of the follow-up IAS scores $(\mathrm{F}=$ 2.50 , df $=6,54, \mathrm{p}<0.05$ ) and $18.8 \%$ of the change between baseline and follow-up $(\mathrm{F}=4.66, \mathrm{df}=3,57, \mathrm{p}<$ $0.01)$ were explained independently from the pre-treatment IAS scores.

\section{Discussion}

Although CBT is known to be generally effective for patients suffering from unclear medical symptoms and health anxieties, not all patients respond to treatment or reach clinically relevant improvements. We have therefore conducted a prospective study aiming at identifying prognostic factors for treatment response. CBT was applied to hypochondriacal inpatients in a natural clinical setting and a large number of potential predictors were assessed prior to treatment. Outcome was then evaluated immediately after the end of the treatment and once more two years later. Because almost nothing is known from the existing literature about predictors of treated hypochondriasis, the primary aim of our study was not to test the hypothesized predictive value of specific variables but rather to search for baseline conditions explaining the outcome and further course of the disorder.

About $60 \%$ of our patients reached considerable improvements or were no longer hypochondriacal after treatment. Responders and non-responders could be differentiated on several baseline variables. Non-responders 
were more hypochondriacal, had more somatization symptoms and general psychopathology, reported more dysfunctional cognitions related to their bodily functioning, had higher levels of psychosocial and work disability, and showed an increased pattern of health care utilization with more days of hospital treatment and higher inpatient and medication expenses. Most of these variables predicted, independently from each other, the degree of hypochondriasis at post-treatment and follow-up. Multiple regression analysis showed that the combined predictors explained $58.9 \%$ of IAS variance at post-treatment and $41.4 \%$ of IAS variance at follow-up. It is worth noting that sociodemographic factors, comorbidity and chronicity were no significant predictors.

A second result from our study is that changes occurring during treatment or between baseline and follow-up were less strongly predictable. However, dysfunctional cognitions as well as work disabilities were significantly associated with direct treatment effects, each variable explaining about $6 \%$ of variance. Higher degrees of disturbance in both variables were associated with less improvement. The long-term changes between baseline and follow-up were linked to pre-treatment hypochondriasis, psychopathology, inpatient costs and days in hospital. If combined, these four variables accounted for about $25 \%$ of the variance. Thus, a substantial degree of the patients' course during the follow-up period could be predicted from pre-treatment characteristics. The results also indicate that patients with lower degrees of psychopathology or psychosocial impairments develop better during or after treatment. The severity of the disorder is therefore a clear negative predictor for treatment outcome. This finding corresponds to research in other areas showing that treatment effects for many other mental disorders seem to be generally more favorable in patients with relatively moderate symptomatology (e.g., for depressive disorder see Sotsky et al. [38]).

Although this study represents a first step to identify predictors for hypochondriasis, some methodological limitations should be mentioned. First, our sample was drawn from an inpatient population which may differ from outpatients with respect to the severity and chronicity of symptomatology. Second, since not all patients fulfilled the strict DSM-IV criteria of hypochondriasis, the nature of our sample is likely to be somewhat more heterogeneous than according to usual clinical classification. Third, the response criterion of 20\% improvement was chosen rather arbitrarily and a lower proportion of responders would have been identified using a more restrictive criterion (for example, $30.2 \%$ of the sample achieved a $50 \%$ reduction). Our results can therefore be interpreted as including both patients with complete as well as partial remission (incomplete recovery). Fourth, while our patients received daily intense treatment with multiple components, usual outpatient CBT is limited to one weekly session and only one therapist is involved. It is possible that a different pattern of predictors would be found in other settings. We wish to emphasize that although our treatments were not strictly standardized with respect to duration and contents, prognostic factors were evaluated under the naturalistic conditions of a regular health care setting. Other strengths of the present study are the relatively large sample size, the assessment of various hypochondriasis-related variables and the long follow-up period.

Special efforts should be made to distinguish the natural course of hypochondriacal disorder from the course influenced by treatment, although such research is often difficult for methodological and ethical reasons. An early study of treated hypochondriasis, employing explanatory psychotherapy as well as medication, was conducted by Kellner [30] with the result that favorable outcome two years later was associated with shorter illness duration and absence of personality disorder. Only a few naturalistic studies have used a prospective design to re-assess hypochondriacal patients after longer periods of time [12, 39-42]. One major problem of these studies is that treatment between inception and follow-up was not systematically controlled for. Untreated patients were not distinguished from patients who had received different treatments of different intensities. However, these studies have tentatively indicated the existence of some general prognostic factors. For example, better outcome seems to be associated with less medical morbidity and less comorbid major depressive and anxiety disorders at inception [12], shorter duration of hypochondriasis, lower neuroticism scores and the demographic variables of being employed and married [39], and with a less pathological combination of somatization, amplification of bodily sensations and attribution of symptoms to disease [40, 41]. Most of these factors have not been confirmed consistently enough and therefore do not yet constitute a comprehensive model.

To summarize, the present study has shown that response to CBT and further development of hypochondriacal patients in the two years following treatment can be predicted significantly by a number of pre-treatment variables. The strongest predictors were dysfunctional cognitions and disability at work for short-term treatment effects, and the degree of pre-treatment hypochondriasis, 
general psychopathology, inpatient treatment costs and days in hospital for effects in the follow-up period. These results may enhance the ability of the clinician to make a more realistic prognosis about expected treatment outcomes.

\section{Acknowledgements}

We wish to thank Marian Cebulla, Hans-Jürgen Korn and Reiner Kroymann for their collaboration in this study.

\section{References}

1 American Psychiatric Association: Diagnostic and Statistical Manual of Mental Disorders, ed 4. Washington DC, American Psychiatric Association, 1994.

2 Fava GA, Molnar G, Zielezny M: Health attitudes of psychiatric inpatients. Psychopathology 1987;20:180-186.

3 Noyes R, Kathol RG, Fisher MM, Phillips BM, Suelzer MT, Woodman CL: Psychiatric comorbidity among patients with hypochondriasis. Gen Hosp Psychiatry 1994;16:78-87.

4 Barsky AJ, Wyshak G: Hypochondriasis and somatosensory amplification. Br J Psychiat 1990; 157:404-409.

5 Rief W, Hiller W, Margraf J: Cognitive aspects of hypochondriasis and the somatization syndrome. J Abnorm Psychol 1998;107:587-595.

6 Rief W, Auer C: Is somatization a habituation disorder? Physiological reactivity in somatization syndrome. Psychiatry Res 2000;101:6374.

7 Gureje O, Üstün TB, Simon GE: The syndrome of hypochondriasis: A cross-national study in primary care. Psychol Med 1997;27: 1001-1010.

8 Hiller W, Rief W, Fichter MM: How disabled are patients with somatoform disorders? Gen Hosp Psychiatry 1997;19:432-438.

9 Fava GA, Sonino N: Psychosomatic medicine: Emerging trends and perspectives. Psychother Psychosom 2000;69:184-197.

10 Barsky AJ: Amplification, somatization, and the somatoform disorders. Psychosomatics 1992;33:28-34.

11 Barsky AJ, Cleary PD, Sarnie MK, Klerman GL: The course of transient hypochondriasis. Am J Psychiatry 1993;150:484-488.

12 Robbins JM, Kirmayer LJ: Transient and persistent hypochondriacal worry in primary care. Psychol Med 1996;26:575-589.

13 Bouman TK, Visser S: Cognitive and behavioural treatment of hypochondriasis. Psychother Psychosom 1998;67:214-221.

14 Warwick HMC, Salkovskis PM: Cognitive-behavioral treatment of hypochondriasis; in Starcevic V, Lipsitt DR (eds): Hypochondriasis: Modern Perspectives on an Ancient Malady. New York, Oxford University Press, 2001, pp 314-328.

15 Warwick HMC, Clark DM, Cobb AM, Salkovskis PM: A controlled trial of cognitivebehavioural treatment of hypochondriasis. Br J Psychiatry 1996;169:189-195.
16 Clark DM, Salkovskis PM, Hackmann A, Wells A, Fennell M, Ludgate J, Ahmad S, Richards HC, Gelder M: Two psychological treatments for hypchondriasis. Br J Psychiatry 1998; 173:218-225.

17 Visser S, Bouman TK: The treatment of hypochondriasis: exposure plus response prevention vs cognitive therapy. Behav Res Ther 2001;39: 423-442.

18 Kroenke K, Swindle R: Cognitive-behavioral therapy for somatization and symptom syndromes: a critical review of controlled clinical trials. Psychother Psychosom 2000;69:201215.

19 Rief W, Hiller W, Geissner E, Fichter MM: A two-year follow-up study of patients with somatoform disorders. Psychosomatics 1995;36: 376-386.

20 Speckens AEM, van Hemert AM, Spinhoven P, Hawton KE, Bolk JH, Rooijmans HGM: Cognitive behavioural therapy for medically unexplained physical symptoms: A randomized controlled trial. BMJ 1995;311:13281332.

21 Speckens AEM, van Hemert AM, Spinhoven P, Bolk JH: The diagnostic and prognostic significance of the Whitely Index, the Illness Attitude Scales and the Somatosensory Amplification Scale. Psychol Med 1996;26:1085-1090.

22 First MB, Spitzer RL, Gibbon M, Williams JBW: Structured Clinical Interview for DSMIV Axis I Disorders (SCID-II). Washington DC, American Psychiatric Press, 1997.

23 Hiller W, Zaudig M, Mombour W: Development of diagnostic checklists for use in routine clinical care. Arch Gen Psychiatry 1990;47: 782-784.

24 Hiller W, Zaudig M, Mombour W: IDCL. International Diagnostic Checklists for ICD-10 and DSM-IV. Seattle, Hogrefe \& Huber Publishers, 1996.

25 Kellner R: Manual of the IAS (Illness Attitude Scales). Albuquerque, University of New Mexico, 1981.

26 Kellner R: Illness Attitude Scales; in Kellner R (ed): Somatization and Hypochondriasis. New York, Praeger-Greenwood Publishers, 1986, pp 319-324.

27 Fava GA, Grandi S: Differential diagnosis of hypochondriacal fears and beliefs. Psychother Psychosom 1991;55:114-119.

28 Hiller W, Rief W, Fichter MM: Dimensional and categorical approaches to hypochondriasis. Psychol Med, in press.
29 Pilowsky I: Dimensions of hypochondriasis. $\mathrm{Br}$ J Psychiatry 1967;113:89-93.

30 Kellner R: Prognosis of treated hypochondriasis. Acta Psych Scand 1983;67:69-79.

31 Fava GA, Grandi S, Rafanelli C, Fabbri S, Cazzaro M: Explanatory therapy in hypochondriasis. J Clin Psychiatry 2000;61:317-322.

32 Rief W, Hiller W: Somatisierungsstörung und Hypochondrie [Somatization disorder and hypochondriasis: a treatment manual]. Göttingen, Hogrefe Publishers, 1998.

33 Rief W, Hiller W, Heuser J: SOMS - Screening für Somatoforme Störungen. Manual zum Fragebogen [SOMS - The screening for somatoform symptoms - Manual]. Bern, Huber Publishers, 1997.

34 Beck AT, Steer RA, Garbin MG: Psychometric properties of the Beck depression inventory: Twenty-five years of evaluation. Clin Psychol Rev 1988;8:77-100.

35 Derogatis LR: The SCL-90-R Manual: Scoring administration procedures for the SCL-90-R. Baltimore, Johns Hopkins University School of Medicine, Clinical Psychometrics Unit, 1983.

36 Barsky AJ, Wyshak G, Klerman GL: The somatosensory amplification scale and its relationship to hypochondriasis. J Psychiatry Res 1990;24:323-334.

37 Chadda RK, Bhatia MS, Shome S, Thakur KN: Psychosocial dysfunction in somatising patients. Br J Psychiatry 1993;163:510-513.

38 Sotsky SM, Glass DR, Shea MT, Pilkonis PA, Collins JF, Elkin I, Watkins JT, Imber SD, Leber WR, Moyer J, Oliveri ME: Patient predictors of response to psychotherapy and pharmacotherapy: Findings in the NIMH treatment of depression collaborative research program. Am J Psychiatry 1991;148:997-1008.

39 Noyes RJ, Kathol R, Fisher M, Phillips B, Suelzer M, Woodman C: One year follow up of medical outpatients with hypochondriasis. Psychosomatics 1994;35:533-545.

40 Barsky AJ, Fama JM, Bailey ED, Ahern DK: A prospective 4-5 year study of DSM-III-R hypochondriasis. Arch Gen Psychiatry 1998;55: 737-744.

41 Barsky AJ, Bailey ED, Fama JM, Ahern DK: Predictors of remission in DSM hypochondriasis. Compr Psychiatry 2000;41:179-183.

42 Simon GE, Gureje O, Fullerton C: Course of hypochondriasis in an international primary care study. Gen Hosp Psychiatry 2001;23:5155. 